\title{
LOS PROBLEMAS DEL SECTOR AGRARIO ALICANTINO Y PROPUESTAS DE DESARROLLO
}

\author{
José Antonio Segrelles Serrano
}

\section{RESUMEN}

Actualmente, la agricultura alicantina se haya sumida en una profunda crisis de carácter estructural que amenaza su futuro. A ello se debe añadir la próxima liberalización del comercio mundial y la competencia de varios países europeos. Es urgente e inevitable llevar a cabo una actuación decidida en varios frentes que proporcione un nuevo impulso a nuestra agricultura y contribuya al desarrollo integral de las áreas rurales. rrollo.

Palabras clave: Alicante, agricultura, problemas estructurales, propuestas de desa-

\begin{abstract}
At present, agriculture in Alicante is starting to fall into a deep structural crisis, that is threatening its future. At the same time, we must to append next free trade in the world and competition with several European countries. It is urgent and inevitable to carry out determined action in different aspects that gives new impulse to our agriculture and helps the integral development at rural areas.
\end{abstract}

Key words: Alicante, agriculture, structural problems, proposals for development.

\section{Principales problemas del sector agrario alicantino}

Los problemas que soporta el sector agrario alicantino son tanto de índole global como particular, es decir, esta zona peninsular debe afrontar una serie de dificultades propias de la provincia y de cada una de sus comarcas, derivadas de sus características físicas, demográficas, agropecuarias y socio-económicas, pero también se ve afectada por la grave situación que en los últimos años atraviesa la agricultura española y europea, sobre todo en un momento en que la economía se halla cada vez más internacionalizada.

Una de las prioridades del Plan de Estabilización de 1959 consistía en transformar las tradicionales sociedad y economía españolas, de características agrícolas y rurales, en un 
nuevo modelo industrial y urbano. Desde comienzos de los años sesenta, se produce un importante crecimiento demográfico y la población se concentra progresivamente en las ciudades, cobran gran relevancia los sectores industrial y terciario, mejoran los transportes e infraestructuras, el turismo comienza a ser un fenómeno de masas y aumenta el poder adquisitivo de los ciudadanos.

El alza de los salarios agrícolas, debido, entre otras razones, al éxodo rural masivo, y las modificaciones que el aumento de las rentas imprime en la demanda de alimentos, son los factores que desencadenan la crisis de la agricultura tradicional. La quiebra de la agricultura tradicional y la penetración del capitalismo en el sector agropecuario acaba con el modelo de subsistencia y comienza a intensificarse la producción para satisfacer la demanda de productos con precios asequibles por parte de la población. Esto provoca la aparición en el medio rural de nuevas relaciones funcionales y socio-económicas que alteran los modos tradicionales (SAENZ LORITE, 1988).

La agricultura adapta sus productos a la demanda del mercado y por ello cobra el dinero que sirve para adquirir otras mercancías que permiten sobrevivir y continuar produciendo al agricultor. Con el paso del tiempo, muchas explotaciones se incluyen en un modo de producción netamente capitalista, donde ya se habla de capital inicial, capital final, inversiones y beneficios (GARCÍA RAMÓN, TULLA, 1981).

De este modo, la agricultura moderna olvida el aprovechamiento de los ciclos biológicos y el reempleo y se basa en los intercambios, el uso de técnicas duras, el empleo de energía no renovable y la aplicación intensiva e indiscriminada de capital. Los nuevos métodos aumentan la productividad y los rendimientos, pero convierten la actividad agraria en un sector altamente dependiente de las fluctuaciones del mercado (SUMPSI, 1982).

La crisis energética de la primera mitad de los años setenta fue la eclosión de un panorama evolutivo que progresivamente desencadenó consecuencias concluyentes, sobre todo para las explotaciones de tipo familiar. El incremento imparable de los precios de los insumos, adquiridos fuera del sector agrario, y la cotización moderada de los productos agropecuarios constituye un binomio agobiante para las rentas de la explotación familiar.

Esta situación se ha ido agravando paulatinamente hasta convertir el aprovechamiento agrario familiar en una actividad crítica e insuficiente (ETXEZARRETA, 1985). Asimismo, la aguda descapitalización que padecen las pequeñas empresas les obliga, si pretenden modernizar o ampliar sus explotaciones, a solicitar créditos que deberán devolverse con intereses altísimos y que las sumen en un círculo vicioso de difícil solución.

Los problemas con los precios, el difícil acceso a las tecnologías modernas, la nula participación en la transformación y comercialización de los productos, la imposibilidad de utilizar economías de escala y de producir a bajo coste, la competencia de las grandes empresas y la política española encaminada a reducir los activos agrarios, dibujan un panorama sombrío para las explotaciones familiares. Las duras condiciones económicas sólo dejan sobrevivir a los más fuertes y supeditan la empresa independiente a los dictámenes de una estructura oligopolística que domina todos los resortes de la cadena productiva.

La inminente liberalización de los mercados y la eliminación de ayudas oficiales a la producción agropecuaria, aspectos auspiciados por Estados Unidos y otros países no europeos en el marco del Acuerdo General sobre Aranceles Aduaneros y Comercio (GATT), contribuye a incrementar el pesimismo. El sector agrario europeo se basa en la explotación familiar y tiene una carga social muy importante, mientras que en el estadounidense predominan las grandes empresas. La diferencia de modelos hace que la agricultura europea sea menos competitiva, pero esto no significa que sea menos eficaz.

El GATT implica que los agricultores y ganaderos europeos se vean obligados a producir menos, reducir sus exportaciones, vender a precios más bajos que las cotizaciones 
actuales y sufrir un aumento de las importaciones al recortar los aranceles. Las repercusiones de estas nuevas directrices por las que se regirá el comercio mundial serán concluyentes para el sector agrario europeo.

Esta situación global perjudica sobremanera a cualquier área agrícola española, y la provincia de Alicante no es una excepción. Incluso podemos aventurar que sus características no son las más idóneas para afrontar con éxito los nuevos retos, fundamentalmente por lo que respecta a ciertas áreas como la Montaña, de preferente aprovechamiento orientado el secano, o el Bajo Segura, en sus regadíos tradicionales. Sin embargo, algunos sectores, como los nuevos regadíos del sur provincial o determinadas zonas de la Marina y del Vinalopó disponen de más medios técnico-financieros, están mejor organizados, disfrutan de mayor rentabilidad y sus productos son mucho más competitivos en los mercados.

El atroz minifundismo imperante en la mayor parte de la provincia (en 1989, el $85 \%$ de las explotaciones con tierras tienen una superficie inferior a 5 hectáreas), así como la acusada parcelación de las explotaciones, supone un obstáculo prácticamente insalvable para cualquier modernización que se pretenda. Asimismo, las posibilidades de comercialización y acceso a los mercados son muy difíciles para las pequeñas explotaciones por la dispersión de la oferta. Según el Censo Agrario de España, mientras en 1962 existían 64.897 explotaciones con tierras, en 1989 se censan 68.493, es decir, tiene lugar un aumento del $5,5 \%$. Este crecimiento del número de explotaciones, contrario a la racionalidad económica, se debe a la demanda de tierras para usos no agrícolas, entre los que destaca el auge de las segundas residencias y la expansión de la agricultura a tiempo parcial.

Otro dato que refleja las deficiencias estructurales de la agricultura alicantina es el acusado grado de parcelación, aunque éste es más o menos agudo según las comarcas. El número medio de parcelas por explotación con tierras es de 2'9 en 1989, cifra que implica una disminución notable de la rentabilidad porque los costes de producción son elevados y cada parcela no garantiza una jornada laboral completa. Existen importantes pérdidas de tiempo por el desplazamiento de una parcela a otra y las dificultades de acceso, que repercuten en la utilización poco racional de los equipos mecánicos.

En este mismo sentido influye el envejecimiento de los empresarios agrícolas y la proliferación de la agricultura a tiempo parcial, pues ambas situaciones fomentan el conservadurismo y repercuten negativamente en la productividad de la explotación. Más del $56 \%$ de los jefes de explotación de la provincia de Alicante superan los 55 años de edad, según el Censo Agrario de España de 1989. El porcentaje de empresarios agrícolas cuya actividad principal es la agricultura sólo es del 54’4\%.

El proceso de mecanización agraria en las grandes explotaciones influye de forma directa en su nivel de ingresos y beneficios, mientras que las pequeñas empresas familiares necesitan mecanizarse para ganar tiempo de trabajo disponible que permita desarrollar actividades paralelas que complementen las rentas de la tierra (PES, 1982).

Estas actividades complementarias suelen ser la ganadería intensiva y la agricultura a tiempo parcial. En cualquier caso, lo que subyace es la insuficiencia de las explotaciones para asegurar las rentas familiares. Cuando en las proximidades de las zonas agrícolas insuficientes existe posibilidad de empleo en la industria o en los servicios, el campesino suele practicar la agricultura a tiempo parcial, pero cuando esta posibilidad es escasa, lo habitual en ciertas áreas es instalar granjas para criar intensivamente cerdos, aves de carne o gallinas ponedoras.

En gran parte de la provincia de Alicante coincide la insuficiencia de las explotaciones, derivada del minifundismo y de la existencia de cultivos poco rentables, y el tiempo libre 
que permite la mecanización, con la cercanía de áreas industriales y de servicios que absorben mano de obra agrícola y fomentan el crecimiento de la agricultura a tiempo parcial.

La agricultura a tiempo parcial puede ser una solución de carácter coyuntural para suavizar la crisis de la agricultura familiar, pero algunos técnicos sostienen que es perjudicial porque retrae las aplicación de tecnología en las explotaciones, repercute negativamente en la productividad y rendimientos, inmoviliza el mercado de la tierra, encarece el precio del suelo e impide cualquier intento de concentración parcelaria.

Tampoco falta quien opina que la agricultura a tiempo parcial es un paso previo al abandono definitivo de la actividad agraria, y muchas veces inclusive del medio rural. Esta modalidad de explotación de la tierra se observa como la pieza fundamental de esa nueva sociedad rural, basada en grandes, tecnificadas y competitivas empresas, que se va gestando desde mediados de los años setenta y en la que no tiene cabida el campesino tradicional. En varias zonas españolas, entre las que no cuenta la provincia de Alicante, la ganadería industrializada, como respuesta a la insuficiencia, bien dimensional, bien económica, de la agricultura, se ha convertido en la actividad que mantiene a los agricultores en el sector e impide el éxodo rural masivo (GOZÁLVEZ, 1987; SEGRELLES, 1993).

Un obstáculo añadido es la carencia de cooperativas agropecuarias y la escasa ligazón existente entre el agricultor y la industria agroalimentaria. El campesino tiene un papel de mero productor y no participa del valor añadido que supone la transformación y comercialización de sus productos. Dicha revalorización no queda en la explotación agropecuaria, sino que va a parar a manos de la agro-industria y de ciertos intermediarios (SEGRELLES, 1992).

Un problema fundamental para el desarrollo agrario de la provincia de Alicante es el de la disponibilidad hídrica, pues muchas cosechas se ven afectadas cada año por la ausencia de precipitaciones o por la mala calidad de las aguas, ya que muchas áreas de regadío están utilizando últimamente aguas hipogeas con alto contenido salino. Se trata de una cuestión muy grave que se añade a los problemas generales de la agricultura y que puede impulsar a los agricultores al abandono de la actividad agraria si no se soluciona a corto plazo. En este sentido destacan los conflictos entre las diferentes Comunidades Autónomas, incluso en el seno de la misma región, por el uso de un bien tan escaso e imprescindible como el agua.

\section{Propuestas para el desarrollo agrario de la provincia de Alicante}

Antes de centrarnos en esta cuestión conviene resaltar el carácter relativo que tiene cualquier propuesta encaminada al desarrollo y competitividad del sector agropecuario en la actualidad. Al margen de las dificultades estructurales, técnicas y comerciales, que con dedicación, interés, constancia e inversiones pueden comenzar a soslayarse en un plazo más o menos largo, el principal escollo estriba en la desigualdad que marca la existencia de países potentes y países modestos. En efecto, intentar desbancar de los mercados a los países más poderosos de la Comunidad Europea (CE) sólo con precios competitivos, resulta una tarea poco menos que imposible por los múltiples intereses existentes, influencia política, poder económico global y dependencia tecnológica.

Los desequilibrios comerciales surgidos a raíz del ingreso español en la CE cobrarán especial intensidad cuando entren en vigor los acuerdos del GATT, firmados en Ginebra durante el mes de diciembre de 1993 tras una larga controversia entre Estados Unidos y la Comunidad Europea. Los países comunitarios con sectores agropecuarios poco competitivos podrían convertirse en receptores netos de los productos excendentarios europeos, ya 
que la reducción de las exportaciones obligaría a Francia, Holanda, Bélgica y Dinamarca a compensar las pérdidas del mercado interno comunitario con una política de precios a la baja o a reducir de forma drástica sus producciones. No sería extraño que la peor parte de esta «guerra comercial» entre Estados Unidos y la CE la llevaran una vez más los países con agriculturas poco capaces de producir a precios bajos y competitivos.

No obstante, ello no debe ser excusa para dejar morir un sector económico consustancial a nuestra cultura y nuestras raíces y que supondría un abandono del medio rural mucho más acusado del que ha tenido lugar hasta ahora. No se deben ahorrar esfuerzos (económicos, técnicos, financieros, intelectuales...) para superar la crisis que padece la agricultura española y alicantina. Y en ello estamos todos comprometidos.

El esfuerzo debe ser especialmente intenso en la provincia de Alicante, donde a pesar de obtener productos con gran demanda en los mercados, el sector agrario soporta en la actualidad una crisis estructural de consecuencias imprevisibles. Si a ello añadimos los problemas coyunturales motivados por la sequía y la escasez de agua, el panorama no puede ser menos que preocupante.

Aun a sabiendas de las dificulades que entraña plantear soluciones viables en un sector donde existen intereses distintos y las decisiones dependen muchas veces de organismos suprarregionales y supranacionales, figuran cuestiones que con determinación, buena voluntad, inversiones y una política integradora y racional, contribuirían a mejorar la situación del sector agropecuario en la provincia de Alicante. De modo general, nuestras propuestas serían las siguientes:

1) Transformación de las estructuras agrarias para paliar el minifundismo y el acusado grado de parcelación, pues la atomización de las explotaciones y la dispersión parcelaria constituyen el principal obstáculo para generar una agricultura desarrollada, rentable y eficaz.

2) Creación de organismos que intervengan en el mercado de la tierra, con el objeto de fomentar una estructura agraria acorde con las necesidades económicas actuales y que permita ampliar las explotaciones a los agricultores a tiempo completo. En Francia y Suecia existen sociedades o juntas que participan en la mayor parte de las transacciones de tierras que se realizan y no permiten ninguna compra-venta si no se pretende con ello una mejora agrícola. Aunque durante las últimas décadas disminuye el número de explotaciones pequeñas en el contexto nacional, en la Comunidad Valenciana, en general, y en la provincia de Alicante, en particular, sucede todo lo contrario. Esto se debe a que a la tierra se le concede más valor simbólico, sentimental y especulativo que económico.

3) Resulta fundamental el cambio de mentalidades y hábitos ancestrales. Es imprescindible el fomento y la difusión de cursos de capacitación profesional para que los agricultores y ganaderos conozcan y apliquen nuevas técnicas y métodos, pero no es menos imperiosa la organización de conferencias, charlas, coloquios, entrevistas personales, etc., para inculcar al campesino las ventajas de una reestructuración agraria profunda y sin paliativos.

4) Fomento del cooperativismo mediante la eliminación de las reticencias que tradicionalmente tiene el campesino a este respecto. El cooperativismo de grandes dimensiones, perfectamente representado en Europa y otras áreas españolas (FERNÁNDEZ, 1985; JULIA, SERVER, 1989), permite a los pequeños y medianos empresarios agrícolas el empleo de tecnología moderna, obviar la dificultad del abastecimiento individual de materias primas e insumos, aprovechar las ventajas de la concentración de la oferta, participar en el valor añadido que conlleva la comercialización de los productos y en el mecanismo de generación de los precios y afrontar desde una posición más sólida los riesgos del mercado. 
Para evitar el fracaso habitual de muchas cooperativas, es necesario que éstas tengan una gestión técnica, racional y profesionalizada, así como que el agricultor olvide el individualismo y acepte las ventajas del trabajo en común.

Una solución interesante para suavizar la saturación del parque de maquinaria agrícola y su subempleo, sería el fomento del cooperativismo también en esta actividad (SEGRELLES, 1989).

5) Se debe desarrollar el sector agroindustrial para adaptarse a las actuales pautas de consumo y potenciar la articulación eficaz de los productores con la industria agroalimentaria, otorgándole la mayor transparencia posible a los canales de comercialización. Si ciertos cultivos tradicionales, y otros nuevos que pudieran difundirse, tuvieran una mayor y más variada transformación (conservas, mermeladas, almíbares, licores, etc.) podrían gozar de más oportunidades en los mercados.

Asimismo, el desarrollo de una agricultura más industrializada y rentable, llevaría consigo el crecimiento de otras actividades relacionadas con el sector agrario: suministradores de insumos, almacenistas de productos agrícolas, almacenistas de productos alimentarios, cámaras frigoríficas, transportistas, venta de maquinaria agrícola e instalaciones de riego, empresas transformadoras de productos agrarios, empresas de exportación, entidades financieras, compañías de seguros, etc.

6) El problema del agua sin duda requiere medidas solidarias y políticas más que económicas. Sin embargo, no debe olvidarse la aplicación de técnicas que permitan el ahorro de los recursos y un uso racional, previo establecimiento de las prioridades, ya que no es probable que la hipotética llegada de aguas del Júcar a la provincia de Alicante beneficie nuestra agricultura de modo global, sin discrimar a ninguna comarca.

7) Para evitar el total desmoronamiento de nuestra agricultura es imprescindible rejuvenecer la población agrícola, mediante una política menos tímida de ayuda a los agricultores jóvenes, e implantar líneas de crédito a bajo interés y subvenciones que permitan modernizar las explotaciones y aumentar su nivel de capitalización. Un ejemplo digno de imitación lo constituye el moderno, tecnificado y rentable sector agropecuario holandés, donde el gobierno trata de crear un ambiente lo más favorable posible para el productor a través de varios organismos específicos y del Rabobank. Esta organización cooperativa de bancos ayuda a las empresas agrarias y se encarga del $90 \%$ de los créditos bancarios concedidos al sector.

8) El agricultor debe estar capitalizado para acometer las inversiones necesarias que modernicen su explotación y obtener así las rentas necesarias para vivir con dignidad. De este modo se paliaría el lastre que para la economía agraria supone la agricultura a tiempo parcial. Un agricultor no se dedica a una actividad a tiempo parcial porque cerca haya posibilidad de empleo en otros sectores, sino porque su explotación es insuficiente. Los Países Bajos tienen las cifras más bajas de la CE en cuanto a agricultura a tiempo parcial cuando su desarrollo industrial y terciario es muy alto.

9) La modernización agraria pasa también por un desarrollo integral de las áreas rurales mediante la dotación de infraestructuras y equipos. En este sentido habría que fomentar la industria agroalimentaria y el cooperativismo como motores del desarrollo rural, ya que así lo demuestran las áreas españolas donde estas actividades están presentes con más o menos intensidad. Las mejoras agropecuaria y rural evitaría la sangría poblacional que padecen muchos núcleos.

10) No creemos que el turismo rural, como nueva opción a la crisis del sector turístico, sea una solución acertada, sobre todo si se convierte en un fenómeno masivo. En poco tiempo podemos convertir muchas áreas rurales en el mismo despropósito en que se ha transformado el litoral, incluso se incrementaría el deterioro del medio natural (erosión, 
contaminación, incendios forestales). Para muchas áreas rurales, el aflujo de consumidores sólo serviría para aumentar la agricultura a tiempo parcial y prolongar la agonía de la actividad agraria un poco más, debido a las rentas complementarias que suministraría el turismo. El turismo rural debe ser una actividad sometida a estrictos controles.

11) Muchas de las medidas mencionadas deben proteger la agricultura familiar, pues ésta puede ser productiva y rentable si dispone de dimensiones óptimas, tecnología, acceso a los mercados y apoyo del Estado en forma de subvenciones y créditos blandos, pero sobre todo si fomenta la cooperación agraria.

Aparte de realizar un esfuerzo denodado para salvar el campo por cuestiones económicas, resultan vitales e insoslayables las circunstancias medioambientales, sociales y culturales. La carga social y el arraigo cultural que tiene el campo europeo y español no existe en los países que preconizan la liberalización internacional del comercio. Al mismo tiempo, la agricultura es una protectora excelente del medio natural. De continuar el camino iniciado corremos el riesgo de perder para siempre la cultura rural. La agricultura, los campesinos, nuestros pueblos, forman parte de un sentimiento generalizado que hunde sus raíces en el pasado. El deber de todo el conjunto de la sociedad, de cada estamento comprometido, es salvaguardar este patrimonio que anida en la memoria colectiva.

\section{Bibliografía}

ETXEZARRETA ZUBIZARRETA, M., La agricultura insuficiente, Madrid, Ministerio de Agricultura, Pesca y Alimentación, 1985, 442 pp.

FERNÁNDEZ, G., El cambio agrario en Galicia, Madrid, Dagur, 1985, 239 pp.

GARCÍA RAMÓN, M ${ }^{a}$.D., TULLA, A., «La unidad de producción campesina y la introducción de las relaciones de producción capitalista en el campo catalán: los casos del Baix Camp de Tarragona y de L'Alt Pirineu», Qüestions de Geografia i Territori Rural, 2, febrero 1981, pp. 5986.

GOZÁLVEZ PÉREZ, V., «La expansión de la ganadería 'integrada' en la provincia de Castellón, apoyo a una agricultura familiar en crisis», Estructuras y regímenes de tenencia de la tierra en España, Madrid, Ministerio de Agricultura, Pesca y Alimentación, 1987, pp. 267-291.

JULIA, J.F., SERVER, R.J., Las Organizaciones y Agrupaciones de Productores Agrarios en España y la CEE, Madrid, Ministerio de Agricultura, Pesca y Alimentación, 1989.

PES GUIXA, A., «El comportamiento de la 'agricultura familiar' en Cataluña a partir de 1960", Investigaciones Económicas, 19, septiembre-diciembre 1982, pp. 73-83.

SEGRELLES SERRANO, J.A., La mecanización agraria en la provincia de Alicante, Valencia, Conselleria d'Agricultura i Pesca, Generalitat Valenciana, 1989, 341 pp.

SEGRELLES SERRANO, J.A., «El cooperativismo ganadero español. Una actividad dinámica e insuficiente ante el Mercado Unico Europeo», Mundo Ganadero, 11, noviembre 1992, pp. 29-33.

SEGRELLES SERRANO, J.A., La ganadería porcina y avícola en España. Del aprovechamiento tradicional al industrializado, Alicante, Secretariado de Publicaciones de la Universidad de Alicante, 1993, $437 \mathrm{pp}$.

SUMPSI, J.M., «La crisis de la agricultura moderna», Agricultura y Sociedad, 25, octubre-diciembre 1982, pp. 185-193. 